\title{
Freeze-Thaw Processes Degrade Post-fire Water Repellency in Wet Soils
}

\author{
Ekaterina Rakhmatulina ${ }^{1}$ and Sally Thompson ${ }^{2}$ \\ ${ }^{1} \mathrm{UC}$ Berkeley \\ ${ }^{2}$ University of Western Australia
}

July 21,2020

\begin{abstract}
Wildfires are a cause of soil water repellency (hydrophobicity), which reduces infiltration while increasing erosion and flooding from post-fire rainfall. Post-fire soil water repellency degrades over time, often in response to repeated wetting and drying of the soil. However, in mountainous fire-prone forests such as those in the Western USA, the fire season often terminates in a cold and wet winter, during which soils not only wet and dry, but also freeze and thaw. Little is know about the effect of repeated freezing and thawing of soil on the breakdown of post-fire hydrophobicity. This study characterized the changes in hydrophobicity of Sierra Nevada mountain soils exposed to different combinations of wet-dry and freeze-thaw cycling. Following each cycle, hydrophobicity was measured using the Molarity of Ethanol test. Hydrophobicity declined similarly across all experiments that included a wetting cycle. Repeated freezing and thawing of dry soil did not degrade soil water repellency. Total soil organic matter content was not different between soils of contrasting hydrophobicity. Macroscopic changes such as fissures and cracks were observed to form as soil hydrophobicity decayed. Microscopic changes revealed by scanning electron microscope imagery suggest different levels of soil aggregation occurred in samples with distinct hydrophobicities, although the size of aggregates was not clearly correlated to the change in water repellency due to wet-dry and freeze-thaw cycling. A nine year climate and soil moisture record from Providence Critical Zone Observatory was combined with the laboratory results to estimate that hydrophobicity would persist an average of 144 days post-fire at this well-characterized, typical mid-elevation Sierra Nevada site. Most of the breakdown in soil water repellency (79\%) under these climate conditions would be attributable to freeze-thaw cycling, underscoring the importance of this process in soil recovery from fire in the Sierra Nevada.
\end{abstract}

\section{Hosted file}

Title_Page.pdf available at https://authorea.com/users/344732/articles/471145-freeze-thawprocesses-degrade-post-fire-water-repellency-in-wet-soils 
Freeze-Thaw Processes Degrade Post-fire Water Repellency in Wet

Soils

Ekaterina Rakhmatulina ${ }^{* 1}$ and Sally Thompson ${ }^{1,2}$
${ }^{6}{ }^{2}$ Civil, Environmental and Mining Engineering, University of Western Australia, 35 Stirling Hwy, Crawley, Western Australia

Abstract

Wildfires are a cause of soil water repellency (hydrophobicity), which reduces infiltration while in-

9 creasing erosion and flooding from post-fire rainfall. Post-fire soil water repellency degrades over time,

often in response to repeated wetting and drying of the soil. However, in mountainous fire-prone forests

1 such as those in the Western USA, the fire season often terminates in a cold and wet winter, during

which soils not only wet and dry, but also freeze and thaw. Little is know about the effect of repeated

freezing and thawing of soil on the breakdown of post-fire hydrophobicity. This study characterized the

changes in hydrophobicity of Sierra Nevada mountain soils exposed to different combinations of wet-

dry and freeze-thaw cycling. Following each cycle, hydrophobicity was measured using the Molarity of

16 Ethanol test. Hydrophobicity declined similarly across all experiments that included a wetting cycle.

17 Repeated freezing and thawing of dry soil did not degrade soil water repellency. Total soil organic mat-

18 ter content was not different between soils of contrasting hydrophobicity. Macroscopic changes such as

19 fissures and cracks were observed to form as soil hydrophobicity decayed. Microscopic changes revealed ${ }^{*}$ Corresponding author: erakhmat@berkeley.edu 

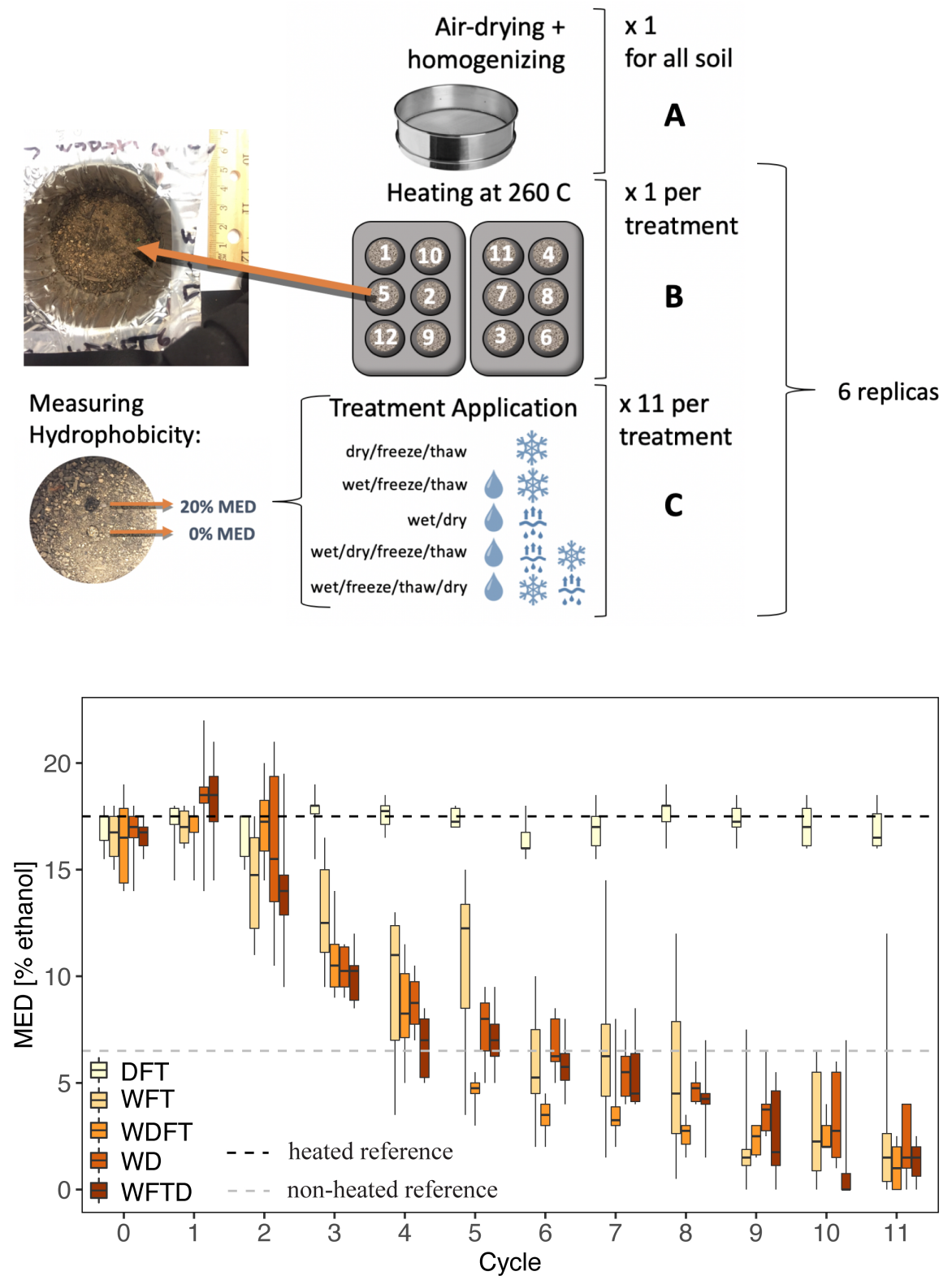

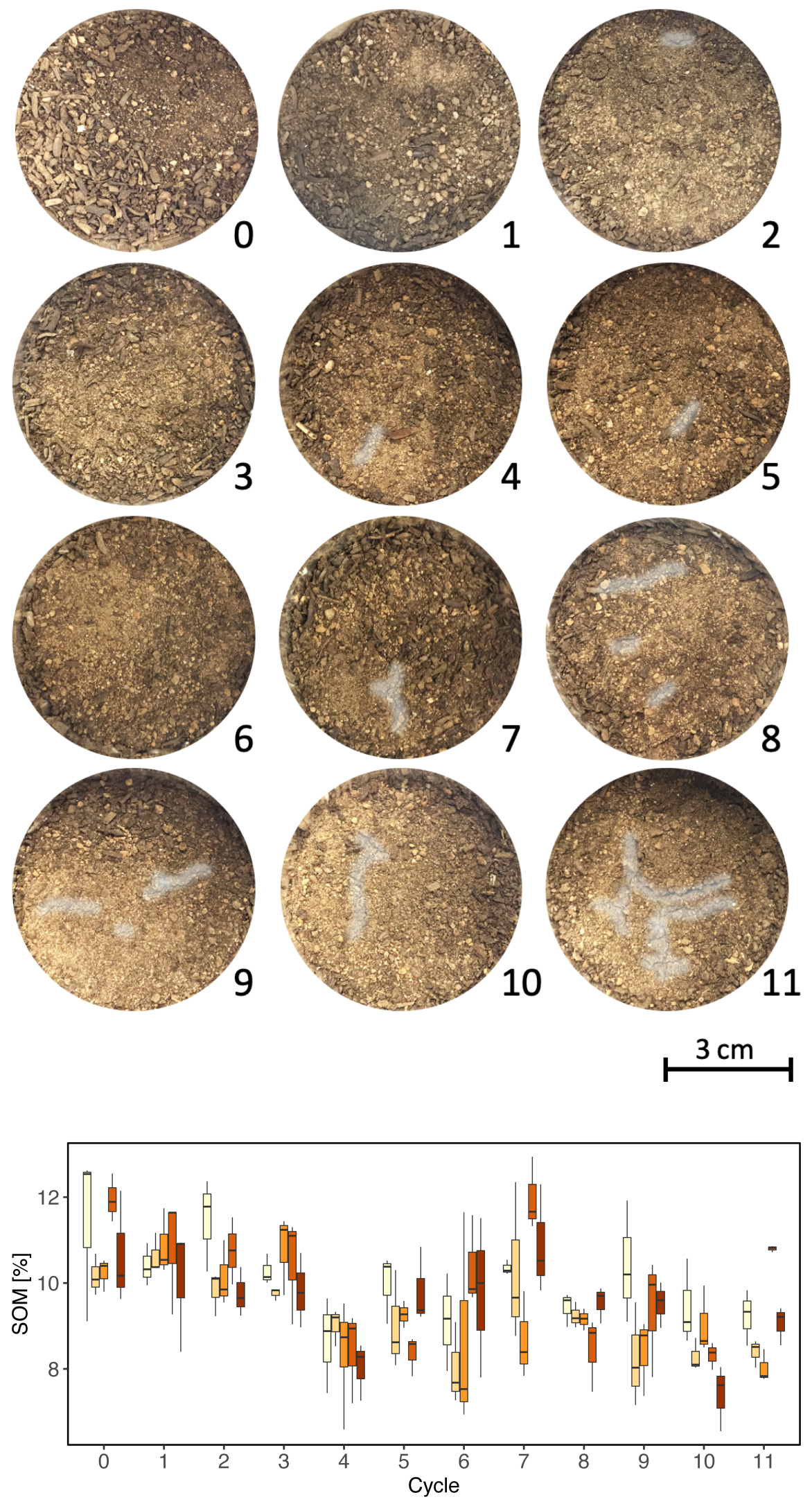

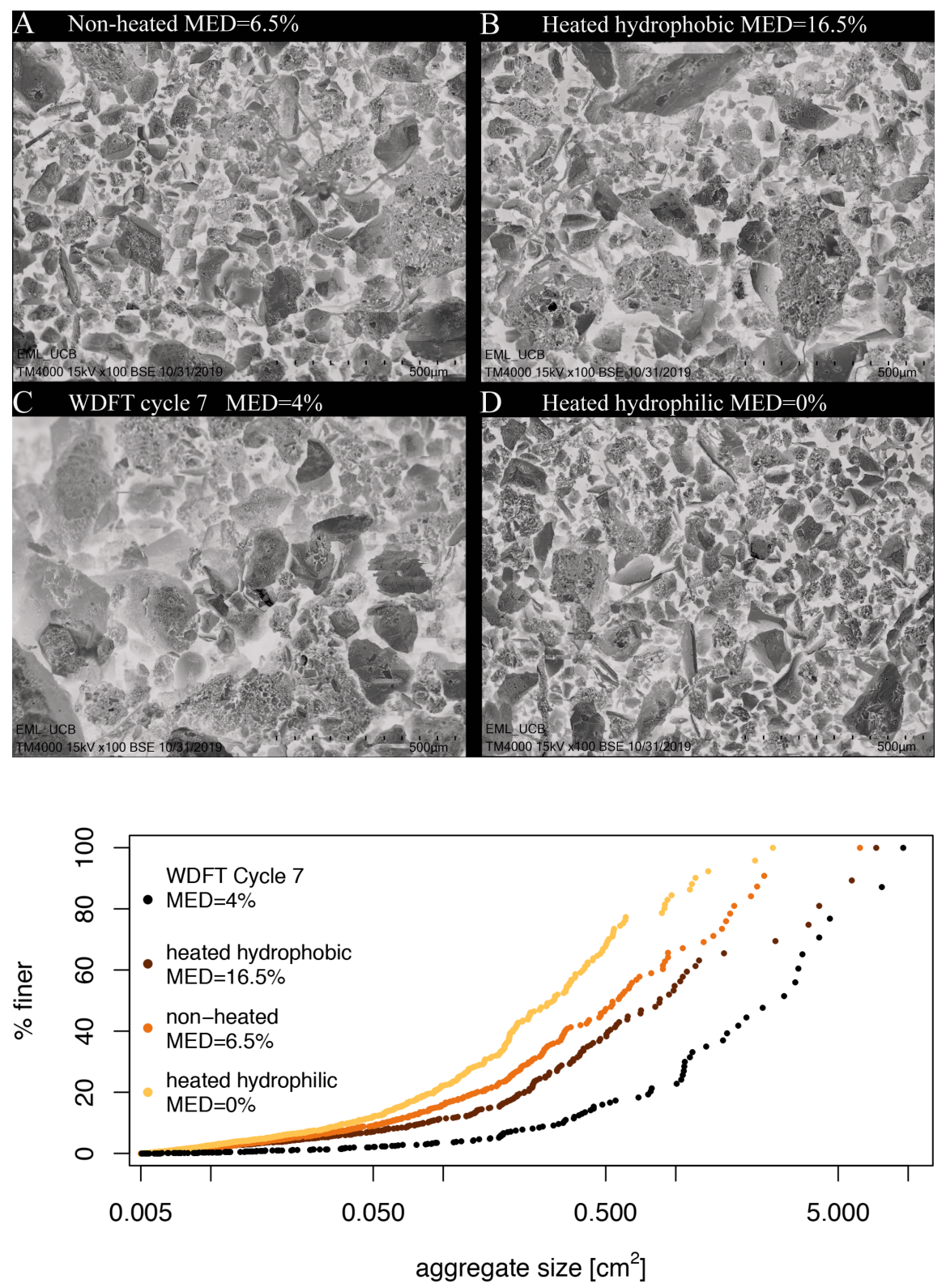

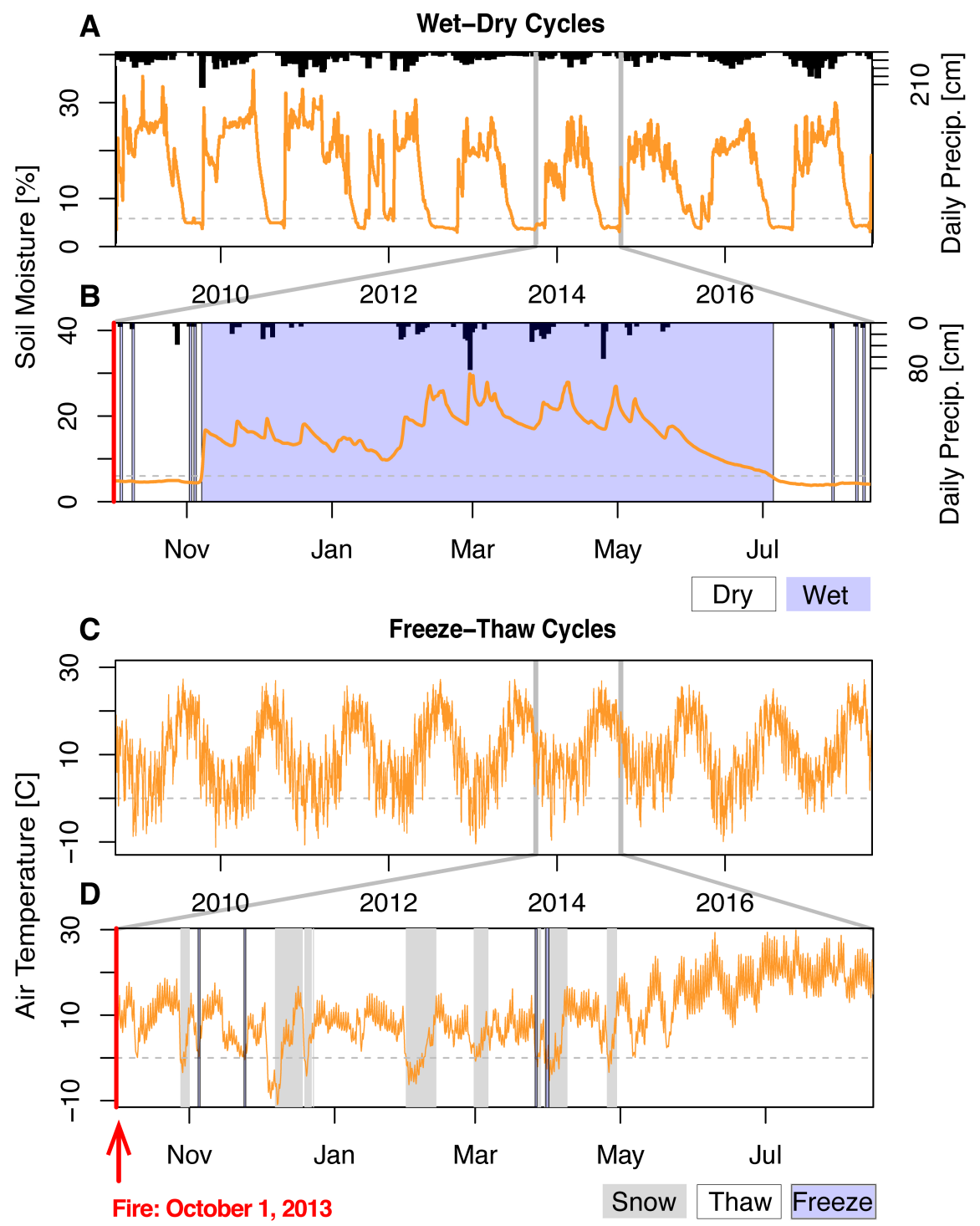


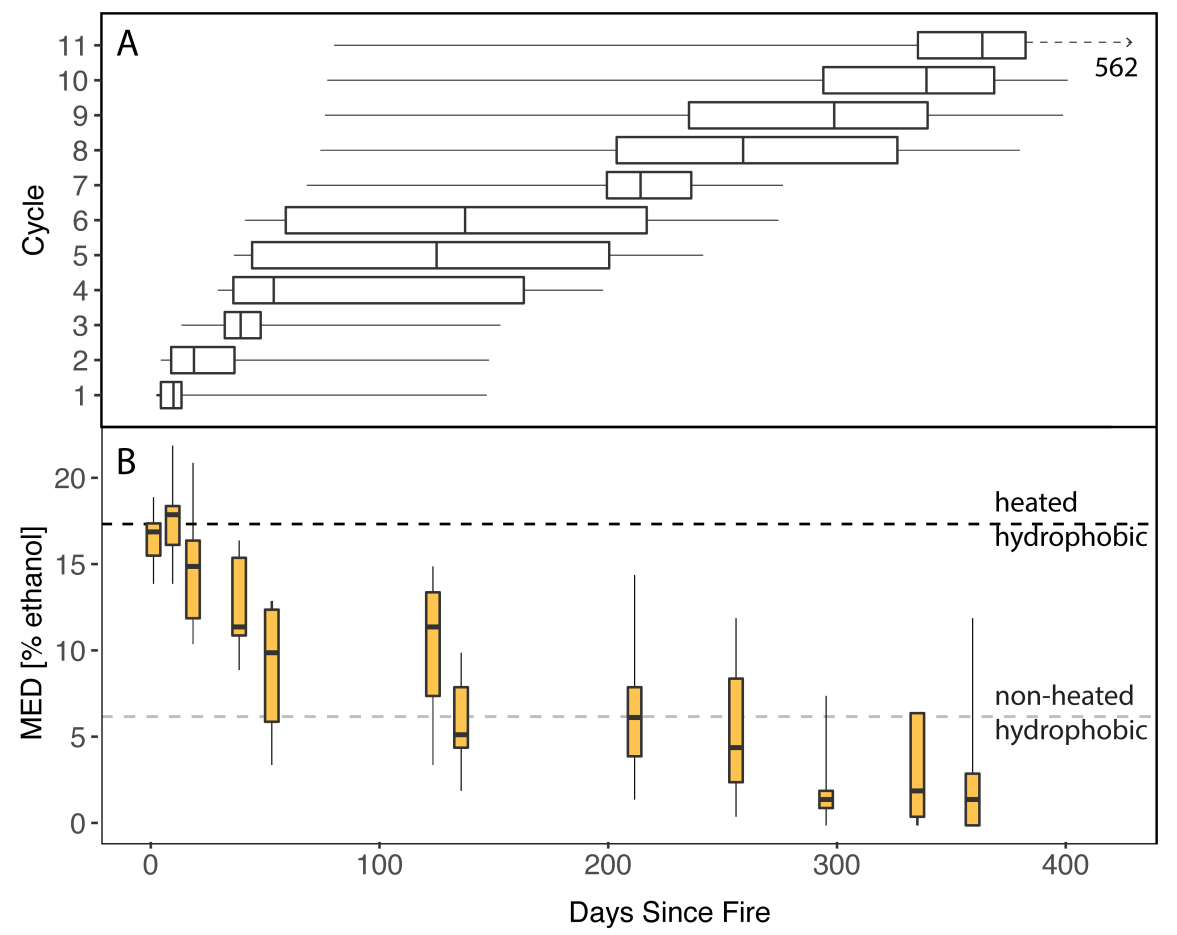

